\title{
Dispositional Effects on Job and Life Satisfaction: The Role of Core Evaluations
}

\author{
Timothy A. Judge \\ University of Iowa
}

\author{
Edwin A. Locke and Cathy C. Durham \\ University of Maryland College Park
}

\author{
Avraham N. Kluger \\ Hebrew University
}

\begin{abstract}
Past research has suggested that dispositional sources of job satisfaction can be traced to measures of affective temperament. The present research focused on another concept, core self-evaluations, which were hypothesized to comprise self-esteem, generalized selfefficacy, locus of control, and nonneuroticism. A model hypothesized that core selfevaluations would have direct effects on job and life satisfaction. It also was hypothesized that core self-evaluations would have indirect effects on job satisfaction. Data were collected from 3 independent samples in 2 countries, using dual source methodology. Results indicated that core self-evaluations had direct and indirect effects on job and life satisfaction. The statistical and logical relationship among core evaluations, affective disposition, and satisfaction was explored.
\end{abstract}

In recent years increasing attention has been given to the hypothesis that factors within the individual, divorced from the attributes of the job, affect the degree of satisfaction experienced on the job. These factors, called dispositions, also are asserted to affect life satisfaction. Although the possible effects of dispositions on satisfaction with the job have been recognized for many decades (e.g., Fisher \& Hanna, 1931; Hoppock, 1935; Locke, 1976; Smith, 1955; Weitz, 1952), it was the work of Staw and Ross (1985) and Staw, Bell, and Clausen (1986) that first provided empirical support for the dispositional hypothesis with respect to job satisfaction. Recent research also suggests that affective temperament is related to subjective

Timothy A. Judge, Department of Management and Organizations, College of Business Administration, University of Iowa; Edwin A. Locke and Cathy C. Durham, College of Business and Management, University of Maryland College Park; Avraham N. Kluger, School of Business Administration, Hebrew University, Jerusalem, Israel. Cathy C. Durham is now at Pepperdine University.

We thank Sharon Buchbinder for her assistance with collection of the physician data. Collection of the data in Israel was funded by a grant received by Avraham N. Kluger from the Recanati Fund of the School of Business Administration at Hebrew University, Jerusalem, Israel.

Correspondence concerning this article should be addressed to Timothy A. Judge, Department of Management and Organizations, College of Business Administration, University of Iowa, Iowa City, Iowa 52242. Electronic mail may be sent to timjudge@uiowa.edu. well-being (Brief, Butcher, George, \& Link, 1993) - a concept equivalent in meaning to life satisfaction.

From this initial base, studies have begun to shed light on the psychological processes underlying the dispositional source of job satisfaction. For example, Weiss and Cropanzano (1996) presented a cognitive model that describes how job reactions result from the correspondence between perceptions of the job and internalized standards. In an empirical study, Brief, Butcher, and Roberson (1995) showed that, when subjected to the same task attributes, individuals' dispositional tendencies affect how they interpret the favorability of these attributes.

Although the last decade of research on the dispositional source of job satisfaction has been successful in establishing a clear link between affective temperament and job satisfaction, further conceptual development in this realm is possible. As House, Shane, and Herold (1996) noted in their recent review of the dispositional literature, affective disposition is only one of many traits that can and should be studied. Further, explanation needs to be provided as to why some people feel happier than others. Advocates of the genetic approach argue that dispositions are innate (Lykken \& Tellegen, 1996); indeed, evidence indicates that the job satisfaction experienced by identical twins reared apart is higher than that of less closely related individuals (Arvey, Bouchard, Segal, \& Abraham, 1989). However, this argument by itself does not illuminate the psychological processes underlying the dispositional source of job satisfaction. Even if it is true that some people's brains are "wired" differently than 
those of others, this cannot be the whole story. What happens after birth and what conclusions people draw from their experiences also profoundly affect people's job and life happiness.

Toward this end, Judge, Locke, and Durham (1997) proposed the concept of "core evaluations," which refer to fundamental, subconscious conclusions individuals reach about themselves, other people, and the world. According to Judge et al., core evaluations may explain, in part, the dispositional source of job satisfaction. Judge et al. argued that people's appraisals of the external world are affected not just by the attributes of objects and people's desires with respect to those objects (e.g., pay in relation to desired pay) but also by the deepest (e.g., metaphysical) assumptions people hold about themselves, other people, and the world. Examples of these premises are "I am weak," "Other people will hurt me," and "The world is a dangerous place" versus "I can handle life's exigencies," "Others can bring me happiness," and "Life is an adventure.' Judge et al. proposed that people who consider themselves to be no good or fundamentally incompetent will react quite differently, for example, to increased job responsibilities than will those who consider themselves to be good and competent. Similarly, people who consider other people to be fundamentally untrustworthy or the world to be a dangerous place will view their jobs in a much less benign way than those with the opposite premises.

The concept of core evaluations, as presented by Judge et al. (1997), which was derived from aspects of eight literatures (philosophy, clinical psychology research, clinical psychology practice, job satisfaction, stress, child development, personality, and social psychology), must be related to and distinguished from other approaches to dispositions. Cantor (1990), for example, discussed cognitive mechanisms pertaining to midrange personality traits that govern how people interpret their environment. An example is schemas, cognitive structures that affect how people process information about themselves and the world. Similarly, Markus (1977) discussed self-schemas that color how people see and interpret reality.

Obviously, there is some relationship between core evaluations and schemas. However, there are two ways in which schemas and core evaluations are different. First, core evaluations are not strictly cognitive; they are evaluations (e.g., I am good; other people are not good; life is dangerous). Second, core evaluations are not midrange traits but rather fundamental traits - fundamental in that they encompass and underlie all other, more specific evaluations (Judge et al., 1997). It should be noted that Cantor (1990) actually distinguished cognitive schemas from dispositions in arguing that schemas may mediate between dispositions and interpretations of the outside world. This

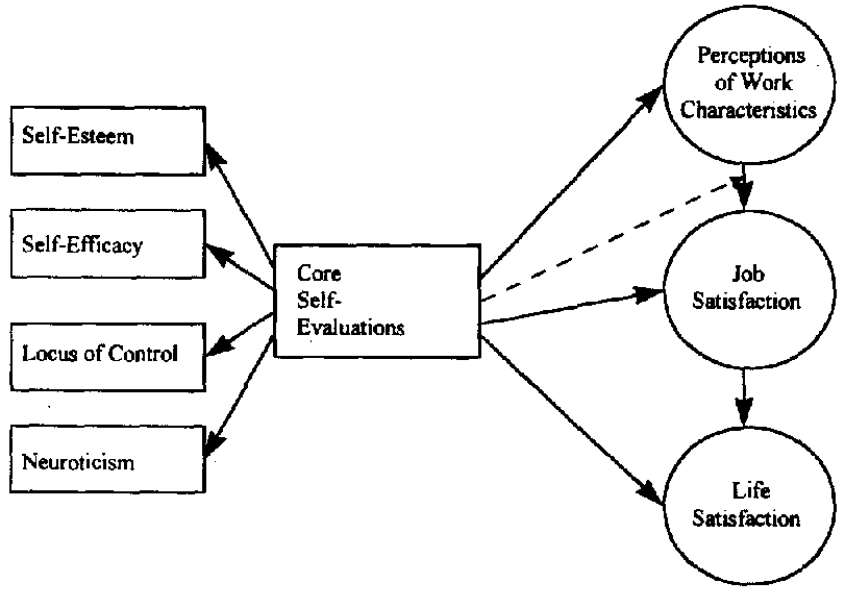

Figure 1. Hypothesized model relating dispositional characteristics to perceptions of intrinsic work characteristics, job satisfaction, and life satisfaction. Dashed line depicts a moderating effect of core self-evaluations on the relationship between perceived work characteristics and job satisfaction. With the exception of the loading of neuroticism on the core self-evaluations factor, all hypothesized linkages were hypothesized to be positive.

implies that schemas are not the same as core evaluations, although they probably are related.

We believe that the concept of core evaluations, whatever its relation to self-schema, is promising as it may further explicate the psychological processes underlying the dispositional source of job satisfaction. We are not arguing that core evaluations represent the cure for all limitations in dispositional research. Rather, we are suggesting that they are a useful addition to our conceptual arsenal and can be used to understand the sources of job and life satisfaction. The particular core evaluations we describe below are based on the theoretical work of Judge et al. (1997). To qualify as a core evaluation, the facet in question had to be both "core" (fundamental) and an evaluation. The three most fundamental evaluations a person can make are with respect to oneself, other people, and reality ( the world). These include, by implication, all lesser evaluations. Below we describe specific evaluations within each of these three broad categories. Figure 1 contains the model tested in the study. As the figure shows, the focus is on core self-evaluations, which are described next. After discussing core self-evaluations, we consider the relationship between them and external core evaluations.

\section{Core Evaluations of the Self}

\section{Self-Esteem}

Self-esteem is the basic appraisal people make of themselves. At its core, self-esteem is the most fundamental 
core evaluation of the self, because it is the overall value that one places on oneself as a person (Harter, 1990). There is considerable evidence that self-esteem is related to job satisfaction (Locke, McClear, \& Knight, 1996). Clausen (1991), working from the same data base as Staw et al. (1986), found that self-esteem was a predictor of job satisfaction later in life for men. Furthermore, Judge and Locke (1993) found that two self-focused items from a measure of affective disposition were mainly responsible for its association with satisfaction with life. Self-esteem may be the source (or an important source) of positive affectivity (PA).

\section{Generalized Self-Efficacy}

Although self-efficacy as treated by Bandura (1997) is task specific, Judge et al. (1997) extended the concept to a global level. Judge et al. defined generalized self-efficacy as one's estimates of one's capabilities to mobilize the motivation, cognitive resources, and courses of action needed to exercise general control over events in one's life. Although it seems reasonable to view self-efficacy in both specific and generalized forms, the relationship of generalized self-efficacy to one's average efficacy ratings across a variety of task-specific situations is yet to be determined. Because generalized self-efficacy can be viewed as reflecting one's perceptions of one's fundamental ability to cope with life's exigencies, it represents a core self-evaluation. Furthermore, general efficacy is typically viewed as being one of the two core components of self-esteem (the other being self-worth; Locke et al., 1996). Thus, it would be expected that generalized selfefficacy would load on the same factor as self-esteem.

\section{Locus of Control}

Locus of control concerns the degree to which individuals believe that they control events in their lives (internal locus of control) or believe that the environment or fate controls events (external locus of control; Rotter, 1966). Although locus of control is theoretically related to generalized self-efficacy, the two concepts differ in one important respect. Self-efficacy pertains to confidence with respect to actions or behaviors, whereas locus is more concerned with confidence in being able to control outcomes. In expectancy theory terms, efficacy pertains more to expectancy and locus more to instrumentality. Although task-specific self-efficacy and locus of control are unrelated (Bandura, 1997), it seems likely that when one considers self-efficacy in its generalized form, its association with locus of control should be stronger. Because both generalized self-efficacy and locus of control represent a belief in oneself relative to one's environment, it is appropriate to construe them as manifestations of one's core self-evaluation. The main reason why individuals with an internal locus of control are more satisfied with their jobs is their perceived ability to control situations. Furthermore, Spector (1982) notes, "Cognitive consistency theory would predict that individuals who have perceived personal control to leave the situation and who choose to stay will tend to reevaluate the situation favorably to retain consistency between their attitudes and behavior"' (p. 490).

\section{Neuroticism}

This is one of the Big Five personality dimensions and constitutes the negative pole of self-esteem. Individuals who score high on measures of neuroticism are likely to be insecure, guilty, and timid (Costa \& McCrae, 1988). Neurotic individuals also are prone to anxiety, which manifests itself in tendencies to be fearful of novel situations and susceptibility to feelings of dependence and helplessness (Costa \& McCrae, 1988). Negative affectivity (NA) is often viewed as a measure of neuroticism, and in fact research indicates that NA and neuroticism are closely related concepts (Larsen \& Ketelaar, 1991). Negative affect and neuroticism act as negative lenses through which the environment is interpreted; for example, high NA individuals rate peers less favorably, view themselves as victims, and tend to be dissatisfied with themselves, with their jobs, and with their lives in general (Clark \& Watson, 1991).

A pertinent question concerning the above list is, Are the above dispositional measures really separate or are they facets of a single, underlying dimension, namely, attitudes toward the self? It is our belief that these specific dispositions represent a common core self-evaluations factor, for several reasons. First, the nature of the specific traits themselves unifies them. Each of the above traits focuses on global evaluations individuals make about themselves or their relation to their environment. Second, an emerging body of research suggests that these dispositions represent a common factor. Judge, Thoresen, and Pucik (1996), analyzing results obtained from five separate studies, found that self-esteem, self-efficacy, locus of control, and positive affectivity loaded on a common factor. Although their analyses did not include neuroticism, logic suggests that neuroticism represents the other side of the same coin. (This is not to deny the possibility it could represent a separate factor)

\section{External Core Evaluations}

External core evaluations are similar to core self-evaluations in that both are fundamental in nature and global in scope. However, the difference between the two is that whereas core self-evaluations are self-appraisals, external 
core evaluations are the appraisals individuals make of their environment. Judge et al. (1997) argued that external core evaluations pertain to other people (trust vs. cynicism) and the world (belief in a benevolent world, belief in a just world).

The importance of developing a sense of trust early in life was noted long ago by Erikson (1950). The opposite of trust is cynicism, the view that other people are "out to get you" and that they lack moral principles, including integrity. Of course, in reality, some people can be trusted and others cannot, but this core evaluation goes deeper than one's journalistic evaluations of others. It pertains to one's deepest convictions about the basic nature of other people. For example, cynicism is sometimes viewed as the basic premise behind Theory $\mathrm{X}$ management. This premise could affect satisfaction with life and one's job to the extent that these involved other people (which is virtually always the case).

Whereas trust concerns the core assumptions individuals hold about other people, belief in a benevolent and a just world pertains to how people evaluate the outside world in general. The premise that the universe is benevolent refers to the belief that happiness and successful value achievement are possible in life, whereas malevolence refers to the belief that one is doomed to failure and frustration (Peikoff, 1991). Such a premise would undercut the pleasure one experienced from success (e.g., "It won't last") and enhance the pain of failure ("This is just the way life is and always will be"'). Ball, Trevino, and Sims (1994) found that individuals who did not believe in a just world had more negative perceptions of the punishment they received than those who had more positive perceptions of justice in life. More broadly, individuals who do not think good work and virtue are rewarded should have a more negative view of life and their jobs than those who believe that life is fair. Obviously, this dimension has some logical link with the trust versus cynicism dimension.

\section{Hypotheses}

Figure 1 contains the hypothesized model tested in this article - in the model, boxes represent exogenous or independent variables, and circles represent endogenous or dependent variables. On the basis of the preceding analysis, we believed that core self-evaluations would contribute to job and life satisfaction. Thus,

Hypothesis 1. The traits constituting core self-evaluations (a) will comprise self-esteem, general self-efficacy, internal locus of control, and nonneuroticism and (b) will be positively related to satisfaction with the job and with life.

Similarly, we predicted that core external evaluations would be related to job and life satisfaction. However, a related question concerns the issue of priority among the various dispositions. There is little in the way of theory to guide us here, but our belief is that the way in which people view themselves is more fundamental and, to a large extent, the source of the way in which people view others and their world. For example, it seems intuitively obvious that people who think poorly of themselves will not see the world as a benevolent or exciting placebecause they will not see themselves as being able to deal with it. On the other side of the coin, it would be hard to see the world as malevolent and dangerous unless one saw oneself as helpless and afraid. And if other people are untrustworthy, individuals with poor self-concepts probably feel it is no less than they deserve. Thus, there was reason to believe that external core evaluations would be related to job satisfaction but would not explain incremental variance in job satisfaction once core self-evaluations are controlled. (Because we believed that external core evaluations would be related to job satisfaction but not incrementally beyond core self-evaluations, external core evaluations are not included in the model in Figure 1.) Although we later tested the relationship of external core evaluations to core self-evaluations and job satisfaction, we only hypothesized the following:

Hypothesis 2. Dispositions pertaining to other people and the world will be positively associated with dispositions pertaining to the self, as well as job and life satisfaction.

The next issue to address pertains to attributes of the job itself. It is well established that certain job attributes, especially attributes of the work such as challenge, significance, task feedback, opportunity for growth, autonomy, and variety are related to job satisfaction (Fried \& Ferris, 1987; Hackman \& Oldham, 1980; Locke, 1976). Are the perceptions of work characteristics influenced by dispositions? Some initial theoretical and empirical work suggests that they are. Larsen and Ketelaar (1991) tested a theoretical rationale for predicting dispositional differences in emotional susceptibility to rewards. Their results showed that extroverted individuals (those predisposed to experience positive affect and positive self-evaluations) were more affected by situations designed to induce positive affect, whereas neurotic individuals (those predisposed to experience negative affect or to hold negative self-evaluations) were less affected by such situations. The application of these findings to employees' reactions to job enrichment is fairly direct. Individuals with positive orientations should react favorably to enriched work whereas individuals with negative orientations should react less favorably, or even negatively, to enriched work. In fact, an earlier study (Kraiger, Billings, \& Isen, 1989) found that positive affect was related to perceptions of task characteristics. What is needed to extend these findings is explicit attention to the aspects of personality that 
may influence the perception of work characteristics, as well as further consideration of the way in which these psychological processes may explain the dispositional source of job satisfaction.

Judge et al. (1997) proposed three possible models of the role of intrinsic job characteristics and the dispositional source of job satisfaction. We have already proposed an effect of core self-evaluations on satisfaction (Hypothesis 1a). However, Judge et al. proposed that both core evaluations and job attributes exert significant, independent influences on job satisfaction. The second model discussed by Judge et al. is a mediator model-perceptions of intrinsic job characteristics mediate (at least partly) the dispositional source of job satisfaction. The mediation hypothesis is also consistent with the argument that people with positive self-concepts have a stronger desire (more motivation) to continue to be happy than people with negative self-concepts. Research by Swann sheds light on these cognitive-motivational processes (Swann, 1992; Swann, Stein-Seroussi, \& Giesler, 1992). According to Swann's theory of self-verification, individuals with positive self-concepts seek situations that will supply them with positive feedback; individuals with negative self-concepts will seek situations providing negative feedback.

Extending self-verification theory, we believe that people may use the perceptions about the nature of their work to reinforce, or detract from, their feelings of self-worth. Individuals with positive core evaluations may seek and categorize information in their work environment that will lead to positive conclusions about their work; individuals with negative core self-evaluations will attend to negative aspects. One way in which individuals with positive selfevaluations may reinforce their self-concept on the job is through their perception of the value of their work. Research directly and indirectly supports this proposition. L. R. James and Jones (1980) found that self-esteem was positively related to perceptions of intrinsic job characteristics, and Judge and Locke (1993) found that perceptions of intrinsic job characteristics partly mediated the relationship between affective disposition and job satisfaction. If the core self-evaluations factor operates in the same way as affective disposition, its influence on job satisfaction also should be mediated, at least in part, by perceptions of work characteristics.

Finally, the moderator hypothesis proposes that dispositions may interact with perceptions of intrinsic job characteristics in influencing job satisfaction. Under the moderator hypothesis, the effect of improving work characteristics would be positive for those with positive core evaluations and neutral (or negative) for those with negative core evaluations. Judge et al. (1997) argued that this type of interaction would be predicted because individuals with poor self-concepts would likely see the negative as- pects of increased job challenge (broader responsibilities leading to more work and the necessity of learning new things), whereas individuals with positive self-concepts would attend to the positive aspects of the change (more interesting work and more influence). In two separate laboratory studies, Brief et al. (1995) and Necowitz and Roznowski (1994) found support for one link in the moderator hypothesis in showing that NA predisposes individuals to attend to the negative aspects of work rewards and enriched tasks.

As discussed by Judge et al. (1997), the main effect, mediator, and interactive models are not mutually exclusive. It is possible that partial forms of all these effects could be found. Because of the conceptual and empirical support for each of the hypotheses, all three are proposed and tested in this article. Thus,

Hypothesis 3a. Main effects: Dispositions and perceptions of work characteristics are independently related to satisfaction with the job such that individuals with positive selfevaluations and who believe their work is challenging will be more satisfied with their jobs.

Hypothesis 3b. Mediator effects: Perceptions of work characteristics partly mediate the effect of dispositions on job satisfaction such that part of the positive influence of core self-evaluations on job satisfaction will be due to a more positive perception of work characteristics.

Hypothesis 3c. Moderator effects: Dispositions will moderate the effect of perceptions of work characteristics on job satisfaction such that individuals with positive selfevaluations will see challenging work as more satisfying than those with negative self-evaluations.

Having presented the hypotheses within the model, we believe there are two additional elements that require some discussion. First, on the basis of the predictions of the job characteristics model, we expected that perceptions of intrinsic job characteristics would be positively related to job satisfaction. Second, we expected that job satisfaction would significantly influence life satisfaction. As Judge and Locke (1993) noted, "An obvious reason for job satisfaction playing a causal role in subjective wellbeing is that it represents a part-whole relationship; that is, the job is a part of life and thus is taken into account when rating overall life satisfaction" (Judge \& Locke, 1993 , p. 485). In fact, the part-whole hypothesis was advanced some time ago and has been supported (see Near, Rice, \& Hunt, 1978; Rice, Near, \& Hunt, 1980). Thus, the conceptual model in Figure 1 displays links from perceptions of work characteristics to job satisfaction and from job satisfaction to life satisfaction.

We should note that the hypothesized model assumes a unidirectional relationship from job satisfaction to life satisfaction. Although this reasoning is consistent with Locke's (1976) part-whole hypothesis, it is also true that other research has found a reciprocal relationship between 
job and life satisfaction (Judge \& Watanabe, 1993). We chose to include only a unidirectional relationship in this study for several reasons. First, it seems likely that much of the effect of life satisfaction reflects a dispositional effect on job satisfaction. In fact, this possibility was directly suggested by Judge and Watanabe. Because we included a core dispositional concept in our model, also including a link from life to job satisfaction would seem redundant. Second, the reciprocal paths between job and life satisfaction found by Judge and Watanabe were very similar to the zero-order correlations. Thus, it is unlikely that including a path from life satisfaction to job satisfaction would affect that path that interests us here, from job to life satisfaction.

\section{Method}

\section{Participants and Procedure}

To strengthen the generalizability of the findings, we collected data from three diverse samples. In an attempt to remove the possibility that the relationships observed were due to self-report bias, we collected data from two sources in all three samples. Participants asked a "significant other" to complete a questionnaire about the participant, evaluating the participant's job satisfaction, life satisfaction, and dispositional characteristics. As it was not feasible to ask significant others to complete a lengthy survey, it was necessary to reduce the length of most of the scales contained in the focal survey (see measures). Specific information on the participants comprising each of these samples, as well as the procedures involved in data collection, are described by sample.

Physician sample. Participants were a sample of 1,300 physicians ( 650 general practitioners and 650 psychiatrists) randomly selected from the American Medical Association's (AMA) Physician Masterfile. The AMA Physician Masterfile contains current and historical information on more than 689,000 U.S. physicians, including AMA members and nonmembers. The random nature of the sampling procedure ensures that the sample selected is representative of the population. We mailed surveys to the sample, and a cover letter assured participants that individual responses were completely confidential. We asked participants to sign an informed consent form. Thirty surveys were returned as undeliverable, and 183 usable surveys were returned by respondents ( $51 \%$ from psychiatrists and $49 \%$ from general practitioners), which represents a $14.4 \%$ response rate. Because of the low response rate, we collected archival data on the demographic characteristics of the sample and population. Analysis of respondents versus nonrespondents revealed no significant differences with respect to age, gender, graduation date from medical school, area of residence, and medical specialty. Thus, it appears that respondents are representative of the larger population of physicians, at least in terms of these variables.

Average age of respondents was 52 years; $87 \%$ of respondents were married, $92 \%$ were White, and $84 \%$ were male. The average physician had been employed in his or her present job for
15 years and worked 50 hours per week. Average annual net income of the physicians was $\$ 120,000$.

We asked all physicians to give a separate questionnaire to a significant other, who was asked in a cover letter to complete the questionnaire independently and return it directly to the researchers. From the pool of 183 surveys returned by the physicians, 165 usable significant-other surveys were returned ( 85 for psychiatrists and 80 for general practitioners), indicating that for $90 \%$ of the physicians who returned surveys, a significant-other survey was also returned. Those who had a returned significant-other survey did not differ from those who did not on any study characteristic. The relationships of the significant others to the respondents were as follows: spouse $=84 \%$, close friend $=11 \%$, sibling $=2 \%$, parent $=1 \%$, and other $=2 \%$.

College graduate sample. Participants were a random sample of 1,086 business school graduates of the University of Maryland. In the survey mailing, a cover letter was attached that assured participants that individual responses were completely confidential. We asked participants to sign an informed consent form. Nineteen surveys were returned as undeliverable, and 158 usable surveys were returned by respondents, which represents a response rate of $14.8 \%$.

The average respondent was 40 years old; $79 \%$ of respondents were married, $96 \%$ were White, and $68 \%$ were male. On average, graduates had been employed in their present jobs for 7 years and worked 47 hours per week. Average annual salary of the graduates was approximately $\$ 74,000$.

As with the physician sample, participants asked a significant other to complete a questionnaire about each business school graduate. One hundred fifty-eight usable significant-other surveys were returned, indicating that for $82 \%$ of the focal respondents who returned surveys, a significant-other survey was also returned. Participants who had a returned significant-other survey did not differ from those who did not. The relationships of the significant others to the respondents were as follows: spouse $=80 \%$, close friend $=15 \%$, parent $=3 \%$, sibling $=1 \%$, and other $=1 \%$.

Israeli sample. We requested 200 students at the Hebrew University to participate in the study. Of this pool, 70 were undergraduate or master's level students taking classes in the social sciences area. These students were working at least 20 hours per week outside of school. Their participation was solicited by posting an announcement on bulletin boards designated for advertising experiments in the social sciences. These students were offered both NIS (Israeli currency) 5.00 and an opportunity to win NIS 200.00 (approximately $\$ 65.00$ ). One hundred and thirty of the students were full-time workers who were studying in continuing education programs offered by the business school and by the education school. We approached these students during class sessions and asked them to participate in the study. We offered the continuing education students NIS 5.00 for participation (most respondents donated the money for a social cause, on the suggestion of one participant).

The average respondent was 33 years old; $53 \%$ of respondents were married, and $57 \%$ were male. On average, respondents had been employed in their present jobs for 6 years and worked 38 hours per week. Average monthly salary of the graduates was approximately NIS $3,970(\$ 1,300)$.

As with the other samples, all participants asked a significant 
other to complete a questionnaire. This questionnaire was supplied in a self-addressed and stamped envelope. We emphasized to the participants that the significant other should fill out the questionnaire in privacy and mail it directly to the researcher without discussing it. We offered respondents an opportunity to register to receive a summary of the research results in a way that protected the anonymity of their questionnaires. The questionnaires of the participant and the significant other were numbered for matching purposes, but anonymity was fully guaranteed. Out of the 200 questionnaire sets that were delivered, $132(66 \%)$ full questionnaire sets that could be matched were returned. Although response rates by sample were not tracked, it is estimated that the response rate for the full-time students was $75 \%$ and $60 \%$ for the continuing education students.

\section{Measures}

We first administered measures to the physician sample. On the basis of preliminary analyses from that sample, we administered slightly shortened surveys to the college graduate and Israeli samples. The college graduate and Israeli surveys were identical except that the Israeli survey was translated into Hebrew. The Israeli version was first translated into Hebrew and then back-translated into English. Both translations revealed very few problems with the translated meaning of the measures. Specific information on the measures is described below. For all of the dispositional and satisfaction measures, we analyzed responses at the scale (as opposed to item) level. Thus, individual items constituting each scale were summed to create a total score. Because the scales comprised different numbers of items, to preserve comparability across the scales, we divided total scores by the number of items comprising the scale.

Overall job satisfaction. We measured overall job satisfaction with five items taken from the Brayfield-Rothe (1951) measure of job satisfaction. These five items were "I feel fairly well satisfied with my present job," "Most days I am enthusiastic about my work," "Each day of work seems like it will never end" (reverse scored), "I find real enjoyment in my work," and "I consider my job rather unpleasant" (reverse scored). In order to ensure that this five-item measure was reliable, we gave it to an independent sample of 222 university employees. The reliability of the five-item scale in this sample was .88 . Furthermore, with data from the present studies, this measure of overall satisfaction correlated, on average, .89 with a composite measure of the facets of the Job Descriptive Index (Smith, Kendall, \& Hulin, 1969). Significant others used the same five items to rate the job satisfaction of their significant other. For both self and significant-other versions, the response scale ranged from 0 (strongly disagree) to 10 (strongly agree), and in each case we averaged scores for the five items to produce a single score for overall job satisfaction. The average correlation between the self and significant-other reports, corrected for unreliability, was $r=.68$.

Life satisfaction. We measured life satisfaction with the five-item Satisfaction with Life Scale (Diener, Emmons, Larsen, \& Griffin, 1985). We asked participants to indicate their agreement with statements such as "In most ways my life is close to ideal," and "I am satisfied with my life," using a scale ranging from 0 (strongly disagree) to 10 (strongly agree). As with the job satisfaction measure, significant others evaluated focal employees' life satisfaction using the same five items. With both self- and significant-other measures, we averaged individuals' ratings to form a single life-satisfaction score. The average corrected correlation between the self and significantother reports was $r=.61$.

Perceptions of work characteristics. We measured perceptions of work characteristics by a five-item version of the Job Diagnostic Survey (JDS; Hackman \& Oldham, 1980). For each of the job characteristics assessed by the JDS (i.e., autonomy, task identity, skill variety, task significance, and task feedback), we asked focal employees to indicate the amount that exists in their jobs, using a scale from 0 (none at all) to 10 ( $a$ tremendous amount). Scores to these five items were averaged to form one score for focal employees' perceptions of intrinsic job attributes.

Self-esteem. We measured self-esteem using items from Rosenberg's (1965) Self-Esteem Scale, which includes items such as "I feel that I am a person of worth, at least on an equal basis with others," and "At times I think I am no good at all" (reverse scored). For the physician data set, we used the full 10-item scale. For the college graduate and Israeli samples, we used a six-item measure. For the physician sample and an independent sample of 147 managers, this six-item measure correlated $r=$ .96 with the 10 -item measure. We averaged scores for the individual items, which used the same 0 (strongly disagree) to 10 (strongly agree) scale as the other measures, to produce a single self-esteem score for each respondent. In all three samples, the significant-other version of the survey used five of these items. The average corrected correlation between the self and significant-other reports was $r=.53$.

Generalized self-efficacy. We developed eight items for this study to assess respondents' generalized self-efficacy. We asked respondents to use a 0 (strongly disagree) to 10 (strongly agree) scale to indicate their level of agreement with statements such as "I am strong enough to overcome life's struggles," and "I often feel that there is nothing that I can do well" (reverse scored). Each individual's mean rating for the eight items formed a single generalized self-efficacy score. For the significant-other survey, we used four of these items. The average corrected correlation between the self and significant-other version was $r=.55$. Because this measure is less widely used than the other measures in this study, we conducted an exploratory factor analysis of items comprising this scale. In the self and significant-other versions, a single factor emerged that explained an average of $62 \%$ of the variance in the items.

Neuroticism. We measured neuroticism by the 12-item Eysenck Personality Inventory Neuroticism Scale (Eysenck \& Eysenck, 1968). We asked individuals to indicate their agreement with statements concerning the frequency with which they experience feelings of irritability, nervousness, worry, embarrassment, or guilt, such as "I'm a nervous person," and "I'm a worrier." The scale ranged from 0 (strongly disagree) to 10 (strongly agree), with high scores indicating a greater degree of neuroticism than low scores. We calculated a single average score for each respondent. The significant-other survey included six neuroticism items. The average corrected correlation between the self and significant-other reports was $r=.56$.

Locus of control. For the physician sample, we measured internal locus of control by the 24-item Internality, Powerful 
Others, and Chance Scale (Levenson, 1981). We asked individuals to indicate their agreement with statements regarding the extent to which they have control over events in their lives, such as "Often there is no chance of protecting my personal interests from bad luck happenings" (reverse scored), and "My life is determined by my own actions." For the college graduate and Israeli samples, we used 12 of these items. For the physician sample and an independent sample of 222 university employees, the 12-item scale correlated .95 and .94 , respectively, with the full 24-item scale. The scale ranged from 0 (strongly disagree) to 10 (strongly agree), with higher scores representing more internal than external locus. We averaged scores for the items to produce a single locus-of-control score for each respondent. For the significant-other survey, we used nine of these items. The average corrected correlation between self and significantother reports was $r=.46$.

External core evaluations. We measured external core evaluations using items we developed for this study. We developed items that assessed each of the three facets of the external core evaluations concept. We developed items measuring trust (e.g., "Most people are good," "Most people will tell a lie if they can gain by it," reverse scored) and belief in a benevolent world (e.g., "It is possible to attain happiness in this world," "Man is doomed to tragedy and despair in life," reverse scored) specifically for this study. We measured belief in a just world using five items from Rubin and Peplau's (1975) Just World Scale. Sample items include "Basically the world is a just place" and "By and large, people deserve what they get." For all items, the response scale ranged from 0 (strongly disagree) to 10 (strongly agree). The external core evaluations scale comprised 15 items for the physician sample and 13 of these items for the college graduate and Israeli samples. We calculated a single average score for each respondent representing his or her average response to the items. The average corrected correlation between the self and significant-other reports was $r=.46$.

Affective disposition. Although not part of our main analysis, the Weitz (1952) Neutral Objects Satisfaction Questionnaire (NOSQ) and the Positive and Negative Affect Schedule (PANAS; Watson, Clark, \& Tellegen, 1988) were included for the purpose of supplemental analyses. The NOSQ assesses affective disposition by asking focal employees to rate their satisfaction with a list of neutral objects common to everyday life (e.g., the way people drive, local newspapers, movies being produced today). Although the original NOSQ contains 25 items, Judge and Locke (1993) reported that 2 items were contaminated with self-esteem. Therefore, we removed these items. The PANAS assesses both PA and NA by asking the focal employees to indicate how often they generally experience 10 positive and 10 negative emotions (e.g., determined, enthusiastic, jittery, afraid). The PANAS scales (average $\alpha=.87$ ) were more reliable than was the NOSQ (average $\alpha=.68$ ).

\section{Results}

\section{Preliminary Analyses}

We conducted three preliminary analyses. First, we computed descriptive statistics (mean and standard deviation) for all the scales measured in the three samples.
Second, we undertook a canonical correlation analysis to determine whether a multivariate relationship existed of the facets of core self-evaluations with job satisfaction, life satisfaction, and perceptions of work characteristics. Thus, to guard against Type I errors, before conducting other analyses, we first computed a canonical correlation to determine whether there is a significant multivariate relationship of the four facets of core selfevaluations with job and life satisfaction and perceived work characteristics.

Table 1 presents descriptive statistics (and scale reliabilities) of study variables for each sample. The table shows that many of the scale means were significantly different across the three samples. In general, the dispositions appeared to be the most positive in the college graduate data set and the least positive in the Israeli data set, but the job and life attitudes were the most positive in the physician data set. That most of the dispositions and attitudes were significantly different across the three samples argued against combining them for the analysis. Accordingly, we analyzed the samples separately. Table 2 contains the intercorrelations (uncorrected for measurement error) of these variables for the physician and college graduate samples. Table 3 contains the uncorrected correlation matrix for the Israeli sample.

Finally, using both self and significant-other reports of the personality traits and work attitudes, results from the canonical correlation analysis revealed that there was a statistically significant relationship $(p<.001)$ between the personality variables (self-esteem, generalized selfefficacy, locus of control, and neuroticism) and the work outcomes (job and life satisfaction and perceived work characteristics). Thus, the factors constituting core selfevaluations appeared to have a significant multivariate effect on job and life satisfaction and perceived work characteristics. This allowed us to proceed with subsequent, more fine-grained analyses.

\section{Meta-Analysis}

In order to estimate the average correlation of the dispositional variables with perceptions of work characteristics and job and life satisfaction, we averaged the correlations from the three studies using meta-analysis (Hunter \& Schmidt, 1990). We corrected the average correlations for sampling error (differences in sample size) and unreliability. Results from this analysis test whether the core self-evaluation facets and external core evaluations are related to job and life satisfaction. It also determines the degree to which the variance in correlations is due to sampling error or true differences across the three studies.

Results of the meta-analysis are presented in Table 4. The table shows that most of the dispositions have moderately strong correlations with the three concepts. As ex- 
Table 1

Descriptive Statistics and Scale Reliabilities for Three Samples

\begin{tabular}{|c|c|c|c|c|c|c|c|c|c|}
\hline \multirow[b]{2}{*}{ Variable } & \multicolumn{3}{|c|}{ Physicians $(N=164)$} & \multicolumn{3}{|c|}{ College graduates $(N=122)$} & \multicolumn{3}{|c|}{ Israelis $(N=122)$} \\
\hline & $M$ & $S D$ & $\alpha$ & $M$ & $S D$ & $\alpha$ & $M$ & $S D$ & $\alpha$ \\
\hline Self-esteem & 8.35 & 1.52 & .90 & 8.59 & 1.19 & .77 & 8.47 & 1.05 & .72 \\
\hline Generalized self-efficacy & 8.34 & 1.39 & .90 & $8.43^{\mathrm{a}}$ & 1.15 & .83 & $8.07^{\mathrm{b}}$ & 1.22 & .81 \\
\hline Locus of control & $6.86^{\mathrm{b}}$ & 1.09 & .87 & $7.31^{\mathrm{c}}$ & 1.38 & .87 & 7.08 & 1.25 & .81 \\
\hline Neuroticism & $3.49^{\mathrm{n}}$ & 2.03 & .93 & $3.71^{\mathrm{B}}$ & 2.01 & .86 & $4.27^{b, c}$ & 1.88 & .85 \\
\hline Extemal core evaluations & $6.26^{\mathrm{a}}$ & 1.18 & .83 & $6.24^{2}$ & 0.97 & .66 & $5.84^{\mathrm{b}, \mathrm{c}}$ & 1.00 & .71 \\
\hline Self-esteem, SOR & 8.47 & 1.73 & .89 & 8.19 & 1.60 & .84 & 8.07 & 1.45 & .84 \\
\hline Generalized self-efficacy, SOR & 8.44 & 1.54 & .82 & 8.43 & 1.39 & .78 & 8.04 & 1.42 & .75 \\
\hline Locus of control, SOR & $7.30^{\mathrm{a}}$ & 1.44 & .84 & $7.11^{\mathrm{a}}$ & 1.38 & .83 & $6.65^{\text {b.c }}$ & 1.44 & .77 \\
\hline Neuroticism, SOR & $2.67^{a, b}$ & 2.09 & .86 & $3.30^{\mathrm{a}, \mathrm{c}}$ & 2.16 & .84 & $4.45^{\mathrm{b} . \mathrm{c}}$ & 2.05 & .82 \\
\hline External core evaluations, SOR & $6.32^{\mathrm{a}}$ & 1.56 & .81 & $6.08^{a}$ & 1.34 & .78 & $5.72^{b, c}$ & 1.10 & .66 \\
\hline Intrinsic job characteristics & $7.72^{\mathrm{a}}$ & 1.24 & .64 & 7.36 & 1.63 & .78 & $7.12^{\mathrm{c}}$ & 1.73 & .78 \\
\hline Job satisfaction & $7.54^{\mathrm{a}, \mathrm{b}}$ & 1.71 & .87 & $6.99^{c}$ & 2.25 & .92 & $6.89^{c}$ & 1.86 & .84 \\
\hline Life satisfaction & 7.10 & 2.04 & .91 & 6.92 & 1.76 & .87 & 6.65 & 1.91 & .88 \\
\hline Job satisfaction, SOR & $7.44^{\mathrm{b}}$ & 1.99 & .91 & $6.71^{c}$ & 2.18 & .91 & 6.92 & 2.02 & .84 \\
\hline Life satisfaction, SOR & 7.17 & 1.72 & .91 & 6.90 & 1.90 & .92 & 6.96 & 1.43 & .85 \\
\hline
\end{tabular}

Note. $\quad$ SOR $=$ significant-other reports.

a Significantly different from Israelis. ${ }^{\mathrm{b}}$ Significantly different from college graduates. ' Significantly different from physicians.

pected, the same source correlations (correlations between self-reports of dispositions and self-reports of the three concepts) are somewhat stronger than the different source correlations (correlations of self-reported dispositions with significant-other reports of the three concepts or correlations of significant-other reports of dispositions with self-reports of the three concepts). In fact, if one analyzes the variance reduction rate (see Burke, Brief, \& George, 1993 , p. 405), the different-source variance shared by core self-evaluations and job satisfaction is $35.7 \%$ lower than the same-source variance shared. For external core evaluations, the different-source variance shared is $66.3 \%$ lower, suggesting that external core evalu- ations are particularly sensitive to common source variance. In general, self-esteem displays the strongest correlations with perceptions of work characteristics and job and life satisfaction. All of the correlations are nonzero, however, as the credibility intervals for all estimates excluded zero. These results support Hypotheses $1 \mathrm{~b}$ and 2: core self-evaluations and external evaluations are significantly correlated with each other (see Tables 2 and 3 ) and with job and life satisfaction. Although not reported in Table 4, results of the meta-analysis indicated that nearly all of the variance in the correlations across studies was due to sampling error. Each correction surpassed the $75 \%$ rule of thumb (Hunter \& Schmidt, 1990) that is used

Table 2

Uncorrected Correlations Among Study Variables for Physician and College Graduate Samples

\begin{tabular}{|c|c|c|c|c|c|c|c|c|c|c|c|c|c|c|c|}
\hline Variable & 1 & 2 & 3 & 4 & 5 & 6 & 7 & 8 & 9 & 10 & 11 & 12 & 13 & 14 & 15 \\
\hline 1. Self-esteem & - & 69 & 45 & -55 & 31 & 51 & 46 & 28 & -33 & 39 & 32 & 40 & 52 & 38 & 54 \\
\hline 2. Self-efficacy & 83 & - & 54 & -49 & 43 & 55 & 52 & 42 & -31 & 39 & 41 & 51 & 43 & 51 & 56 \\
\hline 3. Locus of control & 52 & 50 & - & -38 & 37 & 43 & 49 & 46 & -25 & 31 & 34 & 33 & 32 & 27 & 40 \\
\hline 4. Neuroticism & -71 & -67 & -48 & - & -23 & -42 & -37 & -23 & 59 & -15 & -24 & -32 & -22 & -31 & -37 \\
\hline 5. External core evaluations & 51 & 43 & 57 & -51 & - & 26 & 24 & 22 & -26 & 44 & 21 & 27 & 25 & 25 & 25 \\
\hline 6. Self-esteem, SOR & 44 & 40 & 25 & -48 & 20 & - & 82 & 56 & -55 & 50 & 32 & 29 & 43 & 51 & 69 \\
\hline 7. Self-efficacy, SOR & 35 & 40 & 19 & -46 & 13 & 73 & - & 63 & -50 & 45 & 26 & 29 & 39 & 44 & 54 \\
\hline 8. Locus of control, SOR & 17 & 20 & 38 & -30 & 18 & 46 & 44 & - & -32 & 46 & 39 & 31 & 32 & 45 & 37 \\
\hline 9. Neuroticism, SOR & -35 & -32 & -31 & 52 & -25 & -68 & -55 & -45 & - & -30 & -21 & -12 & -13 & -25 & -36 \\
\hline 10. External core evaluations, SOR & 21 & 17 & 26 & -32 & 30 & 37 & 39 & 32 & -43 & - & 19 & 17 & 30 & 30 & 51 \\
\hline 11. Intrinsic job characteristics & 44 & 36 & 39 & -31 & 40 & 22 & 20 & 22 & -28 & 07 & - & 67 & 27 & 46 & 19 \\
\hline 12. Job satisfaction & 66 & 52 & 38 & -52 & 47 & 32 & 20 & 22 & -26 & 14 & 58 & - & 42 & 65 & 27 \\
\hline 13. Life satisfaction & 51 & 43 & 38 & -46 & 51 & 44 & 32 & 30 & -37 & 25 & 54 & 68 & - & 40 & 55 \\
\hline 14. Job satisfaction, SOR & 38 & 24 & 26 & -43 & 30 & 52 & 38 & 36 & -42 & 41 & 29 & 59 & 51 & - & 45 \\
\hline 15. Life satisfaction, SOR & 31 & 23 & 23 & -43 & 23 & 61 & 53 & 37 & -51 & 41 & 20 & 36 & 58 & 62 & - \\
\hline
\end{tabular}

Note. Decimals are omitted from correlations; correlations from physician data set $(N=164)$ appear below diagonal; correlations from college graduate data set $(N=122)$ appear above diagonal. SOR $=$ significant-other reports. 
Table 3

Uncorrected Correlations Among Study Variables for Israeli Sample

\begin{tabular}{|c|c|c|c|c|c|c|c|c|c|c|c|c|c|c|}
\hline Variable & 1 & 2 & 3 & 4 & 5 & 6 & 7 & 8 & 9 & 10 & 11 & 12 & 13 & 14 \\
\hline 1. Self-esteem & - & & & & & & & & & & & & & \\
\hline 2. Self-efficacy & 63 & - & & & & & & & & & & & & \\
\hline 3. Locus of control & 36 & 53 & - & & & & & & & & & & & \\
\hline 4. Neuroticism & -39 & -33 & -31 & - & & & & & & & & & & \\
\hline 5. External core evaluations & 32 & 18 & 31 & -25 & - & & & & & & & & & \\
\hline 6. Self-esteem, SOR & 36 & 40 & 32 & -14 & 01 & - & & & & & & & & \\
\hline 7. Self-efficacy, SOR & 32 & 42 & 28 & -22 & 09 & 70 & - & & & & & & & \\
\hline 8. Locus of control. SOR & 32 & 38 & 32 & -02 & 16 & 46 & 47 & - & & & & & & \\
\hline 9. Neuroticism, SOR & -03 & -08 & -06 & 34 & 04 & -36 & -36 & -18 & - & & & & & \\
\hline 10. External core evaluations, SOR & 22 & 09 & 21 & -14 & 28 & 35 & 26 & 23 & -25 & - & & & & \\
\hline 11. Intrinsic job characteristics & 17 & 30 & 06 & -05 & -03 & 21 & 21 & 15 & 04 & -01 & - & & & \\
\hline 12. Job satisfaction & 16 & 25 & 22 & -07 & 00 & 35 & 35 & 21 & 01 & 11 & 49 & - & & \\
\hline 13. Life satisfaction & 46 & 34 & 26 & -22 & 32 & 36 & 29 & 36 & -06 & 26 & 15 & 22 & - & \\
\hline 14. Job satisfaction, SOR & 14 & 20 & 24 & 01 & -04 & 37 & 35 & 18 & -05 & 23 & 33 & 57 & 21 & - \\
\hline 15. Life satisfaction, SOR & 23 & 25 & 24 & -08 & 12 & 52 & 30 & 34 & -12 & 30 & 16 & 27 & 50 & 28 \\
\hline
\end{tabular}

Note. Decimals are omitted from correlations. $S O R=$ significant-other reports; $N=122$.

to rule out the presence of true differences across the studies explaining variability in the observed correlations.

Whereas the meta-analysis results suggest that variance in the correlations across the three samples is due to statistical artifacts, a somewhat different approach is to investigate whether sample moderates the effect of core selfevaluations and perceived work characteristics on job satisfaction. Of all possible interactions, results indicated that self-reports of core self-evaluations more strongly predicted self-reported job satisfaction for the physician and college graduate samples than for the Israeli sample. These results do not really contradict the meta-analysis results - the interactions show variability in correlations across the three samples (at least with self-report link- ages), and the meta-analysis results explain the cause of the variability. It should be noted that controlling for sample (using two dummy variables representing the physician and college graduate samples, with the Israeli sample serving as the excluded group) did not affect the relationship between core self-evaluations and job satisfaction.

\section{Usefulness Analysis}

Results from the meta-analysis indicate that a significant univariate relationship exists between core evaluations and job and life satisfaction. As Table 4 shows, the correlations of external core evaluations with job and life satisfaction are positive and moderately strong, indicating

Table 4

Meta-Analysis of Correlations of Dispositions With Perceptions of Intrinsic Job Characteristics and Job and Life Satisfaction

\begin{tabular}{|c|c|c|c|c|c|c|}
\hline \multirow[b]{2}{*}{ Disposition } & \multicolumn{2}{|c|}{$\begin{array}{l}\text { Perceptions of intrinsic job } \\
\text { characteristics }\end{array}$} & \multicolumn{2}{|c|}{ Job satisfaction } & \multicolumn{2}{|c|}{ Life satisfaction } \\
\hline & Same source & Different source & Same source & Different source & Same source & Different source \\
\hline Self-esteem & .43 & .33 & .51 & .36 & .57 & .42 \\
\hline Upper & .29 & .33 & .21 & .24 & .57 & .26 \\
\hline Lower & .57 & .33 & .78 & .47 & .57 & .57 \\
\hline Self-efficacy & .46 & .31 & .47 & .35 & .45 & .38 \\
\hline Upper & .46 & .31 & .34 & .19 & .45 & .19 \\
\hline Lower & .46 & .31 & .59 & .50 & .45 & .57 \\
\hline Locus of control & .38 & .34 & .38 & .29 & .36 & .32 \\
\hline Upper & .16 & .23 & .38 & .29 & .36 & .32 \\
\hline Lower & .58 & .44 & .38 & .29 & .36 & .32 \\
\hline Neuroticism & -.27 & -.22 & -.37 & -.29 & -.35 & -.34 \\
\hline Upper & -.15 & -.04 & -.13 & -.06 & -.22 & -.16 \\
\hline Lower & -.39 & -.40 & -.61 & -.53 & -.47 & -.51 \\
\hline External core evaluations & .29 & .11 & .30 & .22 & .45 & .26 \\
\hline Upper & .21 & .11 & .02 & .15 & .31 & .26 \\
\hline Lower & .55 & .11 & .58 & .42 & .59 & .26 \\
\hline
\end{tabular}

Note. Correlations are averaged and corrected for unreliability and sampling error. Upper and lower limits of credibility intervals are $90 \%$. 
that individuals who are predisposed to hold positive assumptions about their world are more likely to report that they find their jobs and their lives satisfying. Thus, the question of whether both external and self-evaluations are required to explain job and life satisfaction is an important one. We used a regression-based usefulness analysis (Darlington, 1990) to address this issue. In this case, a usefulness analysis entailed determining whether each dispositional concept explained additional incremental variance in job and life satisfaction beyond the variance attributable to the other concept. Because the dispositional variables and job and life satisfaction each were measured with two sources of data, it is possible to estimate four regressions for job satisfaction and four for life satisfaction. Across the three samples, this resulted in 24 regression equations. The usefulness analysis indicated that external core evaluations explained significant incremental variance in job and life satisfaction in only 5 of $24(21 \%)$ regressions, whereas core self-evaluations explained incremental variance in 19 of $24(79 \%)$ regressions. These results support Hypothesis 1b: external core evaluations do not explain further variance in satisfaction when core self-evaluations are controlled. Thus, we did not include external core evaluations in subsequent analyses.

\section{Covariance Structure Analysis}

We used covariance structure analysis, estimated in the present study using LISREL 8 (Jöreskog \& Sörbom, 1993), to test the hypothesized structure of the core selfevaluations concept (Hypothesis 1a), as well as the hypothesized model relating the concept to perceptions of intrinsic job characteristics and job and life satisfaction (Hypotheses 3a and 3b).

Sample size is an important consideration in determining the appropriateness of LISREL estimates (Idaszak, Bottom, \& Drasgow, 1988). Bentler (1985) recommended a sample size to estimated parameter ratio of 5:1 as adequate to achieve meaningful estimates. The sample size to estimated parameter ratios were 11.8:1, 9.2:1, and $8.7: 1$ for the physician, college graduate, and Israeli samples, respectively. Accordingly, we concluded the sample sizes to be adequate.

In order for parameter estimates to be meaningful, the overall fit of the model must be adequate. Accordingly, numerous fit statistics are reported. Conventional fit statistics provided by the LISREL program include chi-square with corresponding degrees of freedom and the goodnessof-fit index. However, because these fit statistics depend on the sample size, four other recommended fit statistics are reported. These are the normed fit index, nonnormed fit index, incremental fit index, and comparative fit index (Medsker, Williams, \& Holahan, 1994). The most common rules of thumb suggest that these latter four fit statis- tics, as well as the goodness-of-fit index, should be greater than .90 (Medsker et al., 1994). Nonsignificant chi-square statistics also indicate a good fit, but they covary with the sample size.

Although nondispositional variables are potentially important in explaining job and life satisfaction, past research has revealed weak effects for objective work inputs (hours worked, education) and outcomes (pay, promotions) in predicting job satisfaction (Judge \& Locke, 1993) and for demographic variables in predicting life satisfaction (Diener, 1984). Therefore, in order to simplify estimation and presentation of the results, we did not include control variables in the LISREL models.

In order to test the hypothesis that the core self-evaluations factor comprises the four dispositional characteristics (self-esteem, self-efficacy, locus of control, and neuroticism), we conducted confirmatory factor analyses of these measures. In the confirmatory factor analyses, we constrained the four concepts to load on one factor. We estimated six confirmatory factor analyses-for each of the three samples, we estimated a confirmatory factor analysis for the self-reported dispositions and another for the significant-other reported dispositions. As can be seen in Table 5, the hypothesized measurement model fits the data well for both the self-reported and significant-other reported traits, and the factor loadings are strong and significant. These results support Hypothesis 1a.

\section{Tests of the Three Models (Hypotheses 3a, 3b, and $3 c$ )}

Main effects model. In order to test the relationship of core self-evaluations with perceptions of work characteristics and job and life satisfaction, we tested three structural models. First, we tested a model relating self-reports of core self-evaluations and perceived work characteristics to significant-other reports of job and life satisfaction. Second, we tested a model relating significant-other reports of core self-evaluations to self-reports of work characteristics and job and life satisfaction. Third, we tested a model using self-reports of all variables.

LISREL estimates for the first model, relating selfreports of core self-evaluations and perceptions of work characteristics to significant-other reports of job and life satisfaction, are provided in Figure 2. Results show that core self-evaluations have moderately strong and significant effects on these three concepts. Finally, across the three samples, perceptions of work job characteristics were significantly related to job satisfaction, which in turn was significantly related to life satisfaction. The fit statistics for the three estimations all suggested that the hypothesized model fit the data well. The poorest fitting model was based on the physician sample - the fit statistics were $\chi^{2}(20, N=165)=33.29, p=.03$; goodness- 
Table 5

Confirmatory Factor Analysis of Core Self-Evaluations Concepts

\begin{tabular}{|c|c|c|c|c|c|c|}
\hline \multirow[b]{2}{*}{ Dispositional concept } & \multicolumn{3}{|c|}{ Self-reports } & \multicolumn{3}{|c|}{ Significant-other reports } \\
\hline & Physicians & College graduates & Israelis & Physicians & College graduates & Israelis \\
\hline Self-esteem & .93 & .82 & .72 & .90 & .89 & .85 \\
\hline Self-efficacy & .89 & .85 & .87 & .80 & .92 & .83 \\
\hline Locus of control & .57 & .60 & .59 & .53 & .65 & .55 \\
\hline Neuroticism & -.76 & -.64 & -.43 & -.74 & -.57 & -.42 \\
\hline \multicolumn{7}{|l|}{ Fit statistics } \\
\hline$\chi^{2}(2 d f)$ & 1.73 & 4.11 & 6.30 & 6.38 & 9.55 & 2.37 \\
\hline Goodness-of-fit index & .99 & .98 & .98 & .99 & .97 & .99 \\
\hline Normed fit index & 1.00 & .98 & .95 & .99 & .97 & .99 \\
\hline Nonnormed fit index & 1.00 & .96 & .89 & 1.00 & .98 & 1.00 \\
\hline Comparative fit index & 1.00 & .99 & .96 & 1.00 & .99 & 1.00 \\
\hline Incremental fix index & 1.00 & .99 & .97 & 1.00 & .99 & 1.00 \\
\hline
\end{tabular}

Note. All factor loadings are significant at the .05 level. All $\chi^{2}$ statistics are nonsignificant.

of-fit index $=.95$; normed fit index $=.95$; nonnormed fit index $=.98$; comparative fit index $=.98$; incremental fit index $=.98$. Even in this case, these fit statistics indicate the model fits the data well.

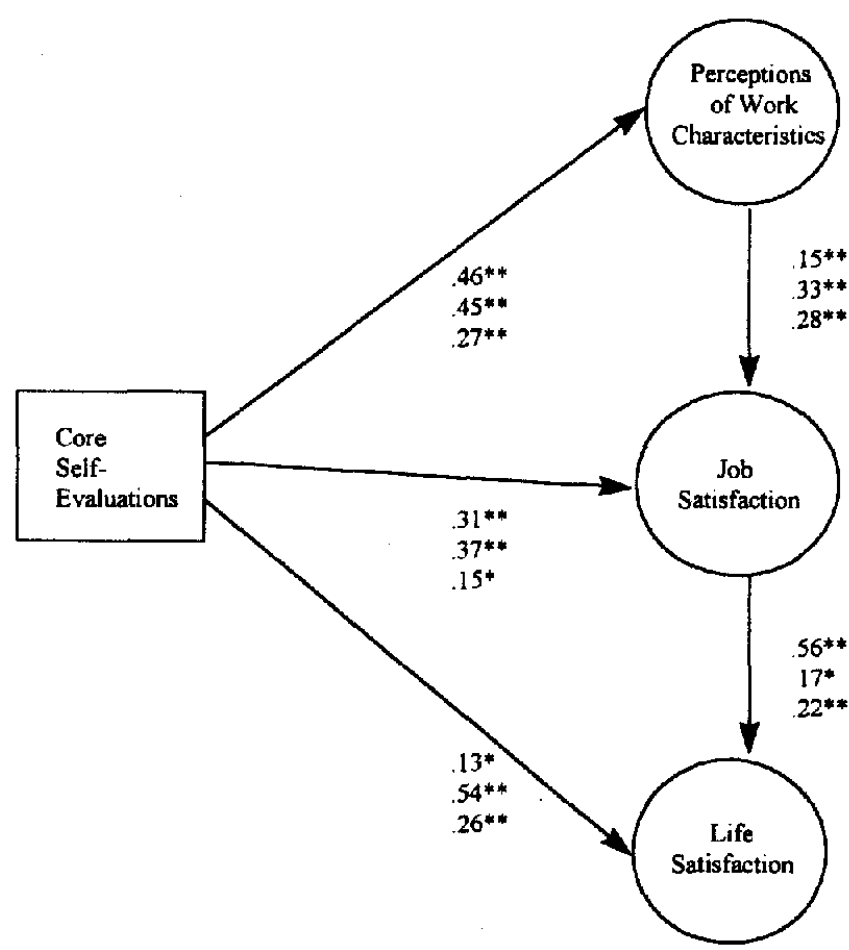

Figure 2. LISREL results of model relating self-reports of dispositions and intrinsic job characteristics to significant-other reports of job and life satisfaction. Estimates in first row represent results from physician data set; estimates in second row represent results from college graduate data set; estimates in third row represent results from Israeli data set. ${ }^{*} p<.05 . * * p$ $<.01$.
Figure 3 provides estimates of a model relating significant-other reports of core self-evaluations to self-reports of work characteristics and job and life satisfaction. As with the other model, we significantly related core self-evalua-

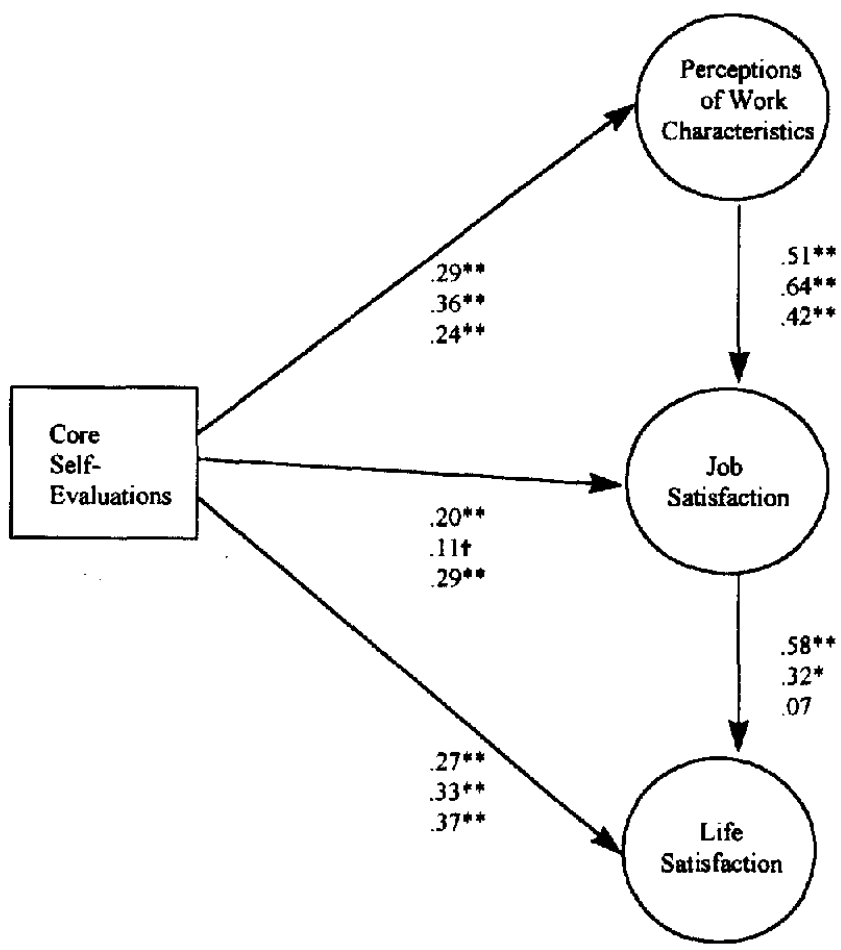

Figure 3. LISREL results of model relating significant-other reports of dispositions to self-reports of intrinsic job characteristics and job and life satisfaction. Estimates in first row represent results from physician data set; estimates in second row represent results from college graduate data set; estimates in third row represent results from Israeli data set. $\dagger p<.10 .{ }^{*} p<.05$. $* * p<.01$. 


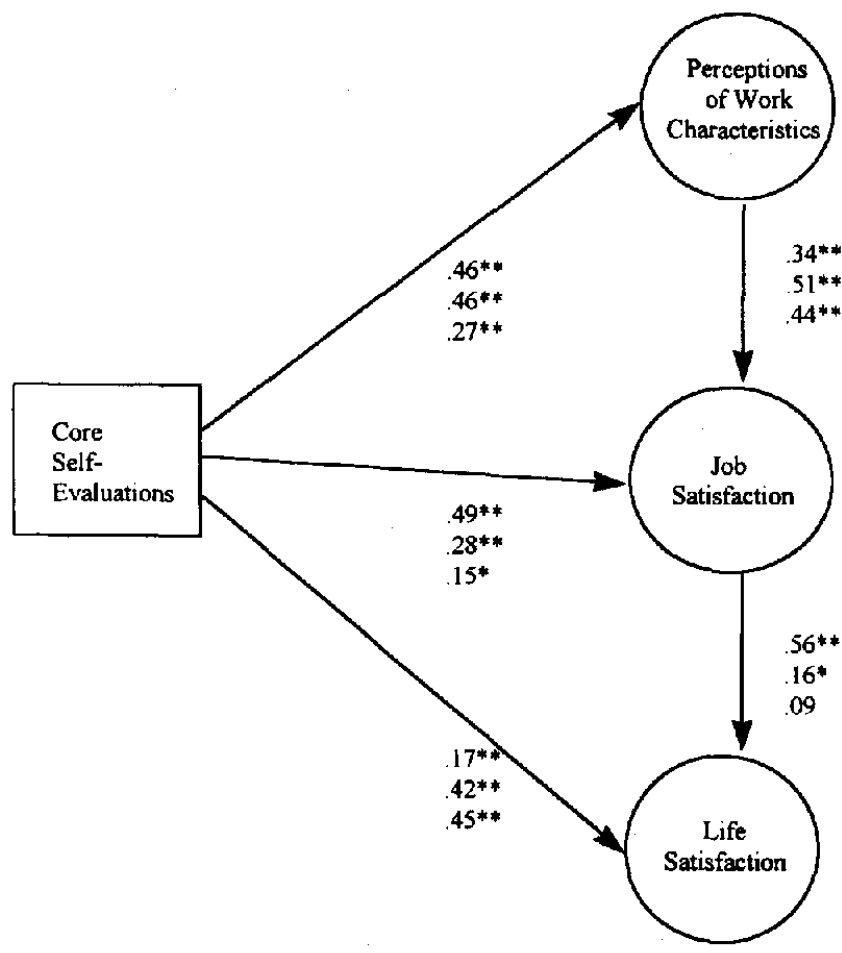

Figure 4. LISREL results from self-report model. Estimates in first row represent results from physician data set; estimates in second row represent results from college graduate data set; estimates in third row represent results from Israeli data set. ${ }^{*} p$ $<.05 .{ }^{*} p<<.01$.

tions to the three concepts across the three samples. Finally, perceptions of work characteristics were significantly related to job satisfaction, and, with the exception of the Israeli sample, job satisfaction was significantly related to life satisfaction. In this model, the poorest fit statistics again were from the physician sample, $\chi^{2}(20, N=165)=25.31$, $n s$; goodness-of-fit index $=.96 ;$ normed fit index $=.95$; nonnormed fit index $=.99$; comparative fit index $=.99$; incremental fit index $=.99$. Again, however, these statistics indicate an excellent fit to the data.

Results of a self-report model, using self-reports of all the concepts, are provided in Figure 4. Similarly consistent with the other models, the relations between core self-evaluations and perceptions of work characteristics and job and life satisfaction were significant and relatively strong (the only exception was the link to life satisfaction for the physician sample). Finally, perceptions of work characteristics were significantly related to job satisfaction, and job satisfaction, with the exception of the Israeli sample, was significantly related to life satisfaction. In this model estimation, even the poorest fit statistics, from the physician sample, $\chi^{2}(20, N=165)=36.06, p=$ .02 ; goodness-of-fit index $=.94$; normed fit index $=.93$; nonnormed fit index $=.97$; comparative fit index $=.97$; incremental fit index $=.97$, indicated that the hypothesized model fit the data well. The models shown in Figures 3 and 4 support Hypothesis $3 a$.

Partial mediation model. Table 6 presents the direct, indirect, and total (direct + indirect) effects of the core self-evaluations concept on job and life satisfaction. In most cases, the direct and indirect effects are significant. Furthermore, the total effects are relatively strong and always significant. This is true even in the cases where the effects are immune to common method variance. In fact, the average total effect, across the estimations and samples, is .50 . This suggests that core self-evaluations display strong relations with job and life satisfaction. We hypothesized that perceptions of work characteristics would mediate the relationship of core self-evaluations with job and life satisfaction. Table 6 shows the indirect effects of core self-evaluations on job satisfaction for the three samples. As the table shows, in all estimations across all three samples, the indirect effects were significant. These results support Hypothesis $3 \mathrm{~b}$ in showing that, in all cases, perceptions of work characteristics partly mediated the relationship between core self-evaluations and job satisfaction.

Moderation model. We tested Hypothesis 3c, that core self-evaluations will moderate the effect of perceived work characteristics on job satisfaction, using hierarchical moderated regression. In this analysis, core self-evaluations and perceptions of work characteristics are entered on the first step of the equation predicting job satisfaction. On the second step, the interaction between core selfevaluations and perceived work characteristics is entered into the equation. If this interaction explains significant incremental variance in job satisfaction, then Hypothesis $3 c$ would be supported. In none of the cases did the interaction explain significant incremental variance in job satisfaction. Because the data sets may be too small to afford sufficient power to test interaction effects, we also tested the interaction using a pooled data set created from the three samples. However, the interaction also did not explain incremental variance using the pooled data set. Thus, Hypothesis $3 \mathrm{c}$ was not supported by the results.

\section{Relation of Core Self-Evaluations to Affective Disposition}

As was noted in the introduction, PA and NA have been the most common measures in investigating the dispositional source of job satisfaction, and affective disposition, measured by the NOSQ, has been used in a number of studies. Therefore, it is relevant to ask, What is the relation between these measures and core evaluations? Core self-evaluations and PA and NA were significantly correlated (average $r=.48$ and $r=-.64$, respectively), as were core self-evaluations and the NOSQ (average $r$ 
Table 6

Direct, Indirect, and Total Effects of Core Self-Evaluations on Job and Life Satisfaction

\begin{tabular}{|c|c|c|c|c|c|c|}
\hline \multirow[b]{2}{*}{ Effect and model } & \multicolumn{2}{|c|}{ Physicians } & \multicolumn{2}{|c|}{ College graduates } & \multicolumn{2}{|c|}{ Israelis } \\
\hline & Job sat. & Life sat. & Job sat. & Life sat. & Job sat. & Life sat. \\
\hline \multicolumn{7}{|l|}{ Dinect } \\
\hline Dispositions (self)-satisfaction (SOR) & $.31 * *$ & $.13^{*}$ & $.37 * *$ & $.54 * *$ & $.15 *$ & $.26 * *$ \\
\hline Dispositions (SOR)-satisfaction (self) & $.20 * *$ & $.27 *$ & .11 & $.33 * *$ & $.29 * *$ & $.37 * *$ \\
\hline Dispositions (self)-satisfaction (self) & $.49 * *$ & $.17 *$ & $.28 * *$ & $.42 * *$ & $.15^{*}$ & $.45 * *$ \\
\hline \multicolumn{7}{|l|}{ Indirect } \\
\hline Dispositions (self)-satisfaction (SOR) & $.07 *$ & $.21 * *$ & $.15^{* *}$ & $.09 *$ & $.08 *$ & $.05 *$ \\
\hline Dispositions (SOR)-satisfaction (self) & $.15^{* *}$ & $.20 * *$ & $.23 * *$ & $.11 * *$ & $.10^{*}$ & .03 \\
\hline Dispositions (self)-satisfaction (self) & $.16^{* *}$ & $.37 * *$ & $.24 * *$ & $.09 *$ & $.12 *$ & .03 \\
\hline \multicolumn{7}{|l|}{ Total } \\
\hline Dispositions (self)-satisfaction (SOR) & $.38 * *$ & $.34 * *$ & $.52 * *$ & $.63 * *$ & $.23^{* *}$ & $.31 * *$ \\
\hline Dispositions (SOR)-satisfaction (self) & $.35^{* *}$ & $.48 * *$ & $.34 * *$ & $44 * *$ & $.39 * *$ & $.40^{* *}$ \\
\hline Dispositions (self)-satisfaction (self) & $.65^{* *}$ & $.54 * *$ & $.52 * *$ & $.51 * *$ & $.27^{* *}$ & $.50 * *$ \\
\hline
\end{tabular}

Note. $\quad$ Sat. $=$ satisfaction; self $=$ self-reports; $\mathrm{SOR}=$ significant-other reports.

${ }^{*} p<.05 . \quad * * p<.01$.

$=.37$ ). Given these substantial correlations, we undertook several analyses to investigate the role of PA-NA and NOSQ relative to core self-evaluations in explaining the dispositional source of job satisfaction.

First, we conducted usefulness analyses (Darlington, 1990) to determine the incremental variance PA-NA, NOSQ, and core self-evaluations explain in predicting job satisfaction. Results of the usefulness analysis revealed that, controlling for PA-NA and the four core self-evaluations traits, the NOSQ explained $0.7 \%$ of the variance in self-reported job satisfaction and $1.1 \%$ incremental variance in job satisfaction reported by significant others. PA and NA explained an average of $22.5 \%$ of the incremental variance in self-reported job satisfaction, controlling for the NOSQ and the four core traits, and an average of $6.5 \%$ of the incremental variance in significant-other reported job satisfaction. Controlling for PA-NA and the NOSQ, the core self-evaluations traits explained an average of $4.2 \%$ of the variance in self-reported job satisfaction and an average of $6.3 \%$ of the variance in job satisfaction reported by significant others. The increments were always statistically significant for PA-NA, nearly always significant for core self-evaluations (with a single exception), and nearly always nonsignificant for the NOSQ (with a single exception).

These results reveal that core self-evaluations explained significant variance in job and life satisfaction not explained by either the NOSQ or the PA-NA scales. What then are we to make of the meaning and relationship of these scales? Given the high correlation of PA-NA, NOSQ, and core self-evaluations, we used exploratory factor analysis to investigate the dimensionality of these measures. With respect to the NOSQ, this measure loaded strongly on the core self-evaluations factor. Further, the main effect and partial mediation models shown came out the same. (This was also true if we used NOSQ by itself in place of core self-evaluations, although the variance explained was smaller.) The results for PA-NA were basically the same. The PA-NA scale loaded on the core self-evaluations factor, and the main effects and partial mediation models were replicated (although the effects were slightly stronger than for core self-evaluations alone). For the Israeli sample, a two-factor solution emerged (NA and neuroticism loaded positively on this factor and self-esteem, self-efficacy, and locus displayed negative cross-loadings ). However, the first factor was the strongest, explaining $47 \%$ of the variance, and all the measures loaded on it (average loading was .60).

The above results indicate that, in different respects, core self-evaluations and the PA-NA scales (a) are getting at something different and (b) have something in common. This poses a conceptual puzzle, which we address in the discussion.

\section{Discussion}

The most important finding of this study is that core evaluations of the self have consistent effects on job satisfaction, independent of the attributes of the job itself. That is, the way in which people see themselves affects how they experience their jobs and even their lives. The critical self-evaluations pertain to self-esteem and general selfefficacy. The factor analysis results indicated that selfesteem and self-efficacy contributed the most to the core self-evaluations concept (see Table 5). The locus of control measure was highly correlated with self-efficacy, and the neuroticism measure was the converse of the positive self-evaluations. Thus people who consider themselves worthy and able to cope with life's exigencies bring a "positive frame" to the events and situations they encoun- 
ter, whereas people who do not see themselves as worthy and able bring a negative frame to the same situations. Mystery writer P. D. James (1971) would agree. In Shroud for a Nightingale, Sister Rolfe describes Detective Adam Dalgliesh as follows, "She thought that he was probably a man who could never imagine himself at a disadvantage in any company since he was secure in his private world, possessed of that core of inner self-esteem which is the basis of happiness" (pp. 132-133).

But how does this frame operate? In part, its effects are direct. We argued elsewhere (Judge et al., 1997) that core self-evaluations are the base on which situationally specific appraisals occur. A useful analogy would be to think of positive situational appraisals as one's height from the ground; the higher one is, the better one feels about the situation (whether that situation be the job, the life, or something even more specific; e.g., perceptions of work characteristics ). Thus, it is as if people with positive core evaluations stand on a higher platform to begin with as compared with those with negative self-estimates. It is not that the situation is irrelevant to situational appraisals; rather, it is that individuals with positive self-concepts see their jobs and lives more positively because they possess the dispositional makeup that allows them to do so.

But there is a second, more indirect way that core evaluations affect job satisfaction. They affect the actual perceptions of the work attributes - attributes which are known to affect how one appraises the job (e.g., autonomy, task significance). This finding suggests that when people describe the attributes of their work, their focus is not just external but also, as least implicitly, internal. That is, individuals with positive self-concepts are more satisfied not only because they feel happier and more in control, but also because they see more variety, challenge, and intrinsic worth in their work. Of course, assessing job attributes involves more than simply sense perception. For example, task significance involves an appraisal of one's work tasks in relation to what is personally important (Locke, 1976). People who feel personally important (i.e., worthy, competent) see their work as important too.

It is notable that both the NOSQ measure of affective disposition, as well as PA and NA, were found to load on the same factor as core self-evaluations. This result is not totally surprising. General orientations to evaluate one's mood and emotional characteristics in a positive way (positive affective disposition) are one manifestation of a general tendency to evaluate oneself positively (positive self-evaluations). Thus, our results suggest that affective disposition, rather than a competing trait in predicting job and life satisfaction, may actually be one of the facets of a broader aspect of the self-concept. It also should be noted that the NOSQ did not explain much incremental variance in job satisfaction controlling for PA-NA and core self-evaluations. This raises questions about whether it should be included, relative to the others, in future dispositional research.

At the same time that PA-NA and core self-evaluations loaded on the same factor, however, each also contributed unique variance to the explanation of job satisfaction. Furthermore, the two types of concepts are actually quite different. One asks, Are you good and efficacious? A second asks, Are you generally in a good (or bad) mood? What then is the conceptual and causal relationship between these two? A full answer to this question will obviously require further research. For example, Judge and Locke (1993) found that the PA-NA scale loaded on a life satisfaction factor. This large factor encompassed six separate scales. However, PA-NA did not load on the life satisfaction factor in this study, but here we used only one scale (of five items) to measure it. Thus, one thrust of future research should involve determining whether the PA-NA measure is dispositional or a direct measure or reflection of life satisfaction itself.

If PA-NA turns out to be an aspect of life satisfaction, then its status would change from that of an independent to a dependent variable. However, let us assume, for the sake of argument, that both PA and NA turn out to be separate from each other and separate from core selfevaluations. Then what? One possibility is that core selfevaluations are, at least in part, a cause of affective disposition, that is, people who like themselves and think they can handle life's challenges are, for that reason alone, in a chronically better mood than those who profoundly doubt themselves. PA-NA could also turn out to have a foot in both camps. It may be a quasi-dispositional measure that reflects both affective disposition and life satisfaction. Possibly both core self-evaluations and affective disposition affect state mood, which in turn affects life satisfaction. Only large-scale studies using multiple measures of each concept and sophisticated analytic techniques will be able to fully address these issues.

Another issue that needs addressing is, What is the cause of self-esteem and general self-efficacy? There are many competing theories of self-esteem. However, Locke et al. (1996) argued that the most plausible theory is Rand's, which asserts that "self-esteem is reliance on one's power to think" (Rand, 1993, p. 181), which means the relentless use of one's conceptual faculty (reason), which implies an active mind-a mind focused on reality, integration, understanding, grasping connections, thinking long range, making deductions and inferences, and increasing the sum of one's knowledge (Binswanger, 1991). Not all researchers agree with a reality-based view of positive self-concept. For example, Taylor and Brown (1988) argued that "positive illusions" (unrealistically positive self-evaluations, exaggerated perceptions of control and mastery, and unrealistic optimism) are an important source of self-esteem and mental health. This view, however, is not the basis of our argu- 
ment-because positive core evaluations are intimately tied to the process of introspection, we assume this process is fundamentally rooted in reality (as opposed to illusion or delusion). This assumption is consistent with a recent critique of Taylor and Brown's argument (Colvin \& Block, 1994). Colvin and Block noted,

We do not believe that cognitive distortions about oneself and one's social surroundings can result in adaptive behavior over long periods of time in a world that provides feedback or reacts back on the individual. Adaptive functioning requires cognizance of antecedent-consequent relations. If individuals distort reality and thereby misjudge consequential, law-reflecting relations, we believe that such individuals must necessarily emit suboptimal, if not maladaptive, behavioral patterns over the long run of a life. (p. 17)

Thus, if an individual's job satisfaction is based on a distorted view of reality, it seems unlikely that these self-deceptive tendencies will prove to be adaptive in the long run.

An important feature of our results is that we replicated the results for the two U.S. samples in another culture, Israel. To our knowledge, this is the first time that dispositional results have been investigated in two cultures at the same time with the same set of measures. In a few cases the Israeli results were weaker than those of the U.S. samples. Thus, there is some evidence that sample moderators exist, but these appear to be due to statistical artifacts and do not affect the relationship between core self-evaluations and job satisfaction. Of course, Israel is in certain respects a very western culture (e.g., profreedom), and its ties to the United States are quite close, but, in other respects, its culture is also dramatically different from that of the United States (Hofstede, 1980). However, because we collected data from only one culture outside the United States, tests of the role of culture as a moderating or mediating variable were not possible. Our only goal was to replicate the results outside the United States. Further work needs to consider this issue explicitly.

This study has several limitations that need to be noted. With respect to the issue of causal inference, it is virtually impossible to do realistic experimental studies in which dispositions are experimentally manipulated. Therefore unequivocal causal statements cannot be made from our data. However, the use of dual source methodology allowed us at least to control possible $r-r$ (response-response) bias. It is encouraging that all three combinations (self-reports of dispositions vs. other reports of satisfaction; other reports of dispositions vs. self-reports of satisfaction; and self-reports of both) obtained the same basic results. As expected, the self-self data showed the strongest effects, but this could have been due to reasons other than bias. For example, individuals often (though not always) know their own attitudes better than do others, because they can observe them directly, through introspection, whereas such attitudes must be inferred by other people.
On the other side of this same coin, the self-significant other correlations of core evaluations were only moderate in size. The number of concepts assessed in this study placed limits on the number of items that could be used to assess each concept on the significant-other survey, which raises concerns over the psychometric equivalence of the measures. However, it should be noted that the full and reduced measures of core self-evaluations correlate similarly with the outcome measures that were equivalent in terms of item content: the self and significant-other reports of job and life satisfaction. The average difference in correlations of the full and reduced trait measures with both measures of job and life satisfaction was only .02 . Furthermore, a confirmatory factor analysis model in which the four self-reported and the four shorter, significant-other reported core traits were constrained to load on a single core evaluations factor, provided factor loadings that were very similar (the average factor loading for the four self-reported traits was .62, and for the shorter [significant-other] measures, the average loading was .64). Although these analyses cannot demonstrate equivalency in the measures, they do tend to suggest it is not a large problem with these data.

The correlations between self and significant-other reports of corresponding personality characteristics were moderate, though they do closely resemble those found in personality research, including research on the Big Five traits (Costa \& McCrae, 1988). Furthermore, using Burke et al.'s (1993) variance reduction rate, the differentsource variance shared by core self-evaluations and job satisfaction was roughly $36 \%$ lower than the same-source variance shared. Are the same source correlations upwardly biased because of common method variance or the omission of a common, unconsidered variable? Or are the different source correlations downwardly biased because one's private self does not always mirror one's public persona? On the one hand, as noted above, individuals potentially know their psychology best because they have first-hand knowledge of it (by introspection); on the other hand, because everyone does not introspect equally well and because some people distort their introspective reports because of defensive processes (Locke et al., 1996), some (though not all) other people can know a given person better than that person knows him- or herself. Who is more accurate in a given case could be determined only by extensive clinical interviewing. Demo (1985) found that self-reported self-esteem was substantially correlated with clinical ratings, an encouraging finding in terms of its implications for our results.

\section{References}

Arvey, R. D., Bouchard, T. J., Segal, N. L., \& Abraham, L. M. (1989). Job satisfaction: Environmental and genetic components. Journal of Applied Psychology, 74, 187-192. 
Ball, G. A., Trevino, L. K., \& Sims, H. P. (1994). Just and unjust organizational punishment: Influences on subordinate performance and citizenship. Academy of Management Journal, 37, 299--322.

Bandura, A. (1997). Self-efficacy: The exercise of control. New York: W. H. Freeman.

Bentler, P. M. (1985). Theory and implementation of EOS: A structural equations program. Los Angeles: BMDP Statistical Software.

Binswanger, H. (1991). Volition as cognitive self-regulation. Organizational Behavior \& Human Decision Processes, 50, 154-178.

Brayfield, A. H., \& Rothe, H. F. (1951). An index of job satisfaction. Journal of Applied Psychology, 35, 307-311.

Brief, A. P., Butcher, A. H., George, J. M., \& Link, K. E. (1993). Integrating top down and bottom-up theories of subjective well-being: The case of health. Journal of Personality and Social Psychology, 64, 646-653.

Brief, A. P., Butcher, A., \& Roberson, L. (1995). Cookies, disposition, and job attitudes: The effects of positive mood inducing events and negative affectivity on job satisfaction in a field experiment. Organizational Behavior and Human Decision Processes, 62, 55-62.

Burke, M. J., Brief, A. P., \& George, J. M. (1993). The role of negative affectivity in understanding relations between selfreports of stressors and strains: A comment on the applied psychology literature. Journal of Applied Psychology, 78, 402-412.

Cantor, N. (1990). From thought to behavior: "Having"' and "doing" in the study of personality and cognition. American Psychologist, 45, 735-750.

Clark, L. A., \& Watson, D. (1991). General affective dispositions in physical and psychological health. In C. R. Snyder \& D. R. Forsyth (Eds.), Handbook of clinical and social psychology (pp. 221-245). New York: Pergamon Press.

Clausen, J. (1991). Adolescent competence and the shaping of the life course. American Journal of Sociology, 96, 805-842.

Colvin, C. R., \& Block, J. (1994). Do positive illusions foster mental health? An examination of the Taylor and Brown formulation. Psychological Bulletin, 116, 3-20.

Costa, P. T., Jr., \& McCrae, R. R. (1988). Personality in adulthood: A six-year longitudinal study of self-reports and spouse ratings on the NEO Personality Inventory. Journal of Personality and Social Psychology, 54, 853-863.

Darlington, R. B. (1990). Regression and linear models. New York: McGraw-Hill.

Demo, D. H. (1985). The measurement of self-esteem: Refining our methods. Journal of Personality and Social Psychology, 48, 1490-1502.

Diener, E. (1984). Subjective well-being. Psychological Bulletin, 95, 542-575.

Diener, E., Emmons, R. A., Larsen, R. J., \& Griffin, S. (1985). The satisfaction with life scale. Journal of Personality Assessment, 49, 71-75.

Erikson, E. (1950). Childhood and society. New York: Norton.

Eysenck, H. J., \& Eysenck, S. B. G. (1968). Manual for the Eysenck Personality Inventory. San Diego, CA: Educational and Industrial Testing Service.
Fisher, V. E., \& Hanna, J. V. (1931). The dissatisfied worker. New York: Macmillan.

Fried, Y., \& Ferris, G. R. (1987). The validity of the job characteristics model: A review and meta-analysis. Personnel Psychology, 40, 287-322.

Hackman, J. R., \& Oldham, G. R. (1980). Work redesign. Reading, MA: Addison-Wesley.

Harter, S. (1990). Causes, correlates, and the functional role of global self-worth: A life-span perspective. In R. J. Sternberg \& J. Kolligan, Jr. (Eds.), Competence considered (pp. 67-97). New Haven, CT: Yale University Press.

Hofstede, G. (1980). Culture's consequences. Beverly Hills, CA: Sage.

Hoppock, R. (1935). Job satisfaction. New York: Harper.

House, R. J., Shane, S. A., \& Herold, D. M. (1996). Rumors of the death of dispositional research are vastly exaggerated. Academy of Management Review, 21, 203-224.

Hunter, J. E., \& Schmidt, F. L. (1990). Methods of meta-analysis. Newbury Park, CA: Sage.

Idaszak, J. R., Bottom, W. P., \& Drasgow, F. (1988). A test of the measurement equivalence of revised Job Diagnostic Survey: Past problems and current solutions. Journal of Applied Psychology, 73, 647-656.

James, L. R., \& Jones, A. P. (1980). Perceived job characteristics and job satisfaction: An investigation of reciprocal causation. Personnel Psychology, 33, 97-135.

James, P. D. (1971). Shroud for a nightingale. New York: Warner Books.

Jöreskog, K. G., \& Sörbom, D. (1993). LISREL 8 user's reference guide. Chicago: Scientific Software.

Judge, T. A., \& Locke, E. A. (1993). Effect of dysfunctional thought processes on subjective well-being and job satisfaction. Journal of Applied Psychology, 78, 475-490.

Judge, T. A., Locke, E. A., \& Durham, C. C. (1997). The dispositional causes of job satisfaction: A core evaluations approach. Research in Organizational Behavior, 19, 151-188.

Judge, T. A., Thoresen, C., \& Pucik, V. (1996, August). Managerial coping with change: A dispositional perspective. Paper presented at the Academy of Management Annual Meetings, Cincinnati, $\mathrm{OH}$.

Judge, T. A., \& Watanabe, S. (1993). Another look at the job satisfaction-life satisfaction relationship. Journal of Applied Psychology, 78, 939-948.

Kraiger, K., Billings, R. S., \& Isen, A. M. (1989). The influence of positive affective states on task perceptions and satisfaction. Organizational Behavior and Human Decision Processes, 44, 12-25.

Larsen, R. J., \& Ketelaar, T. (1991). Personality and susceptibility to positive and negative emotional states. Journal of Personality and Social Psychology, 61, 132-140.

Levenson, H. (1981). Differentiating among internality, powerful others, and chance. In H. M. Lefcourt (Ed.), Research with the locus of control construct (pp. 15-63). New York: Academic Press.

Locke, E. A. (1976). The nature and causes of job satisfaction. In M. D. Dunnette (Ed.), Handbook of industrial and organizational psychology (pp. 1297-1343). Chicago: Rand McNally.

Locke, E. A., McClear, K., \& Knight, D. (1996). Self-esteem 
and work. International Review of Industrial/Organizational Psychology.

Lykken, D., \& Tellegen, A. (1996). Happiness is a stochastic phenomenon. Psychological Science, 7, 186-189.

Markus, H. (1977). Self-schemata and processing information about the self. Journal of Personality and Social Psychology, $35,63-78$.

Medsker, G. J., Williams, L. J., \& Holahan, P. J. ( 1994). A review of current practices for evaluating causal models in organizational behavior and human resources management research. Journal of Management, 20, 439-464.

Near, J. P., Rice, R. W., \& Hunt, R. G. (1978). Work and extrawork correlates of life and job satisfaction. Academy of Management Journal, 21, 248-264.

Necowitz, L. B., \& Roznowski, M. (1994). Negative affectivity and job satisfaction: Cognitive processes underlying the relationship and effects on employee behaviors. Journal of Vocational Behavior, 45, 270-294.

Peikoff, L. (1991). Objectivism. New York: Dutton.

Rand, A. (1993). The new left: The anti-industrial revolution. New York: Penguin (Meridian).

Rice, R. W., Near, J. P., \& Hunt, R. G. (1980). The job-satisfaction/life satisfaction relationship: A review of empirical research. Basic and Applied Social Psychology, 1, 37-64.

Rosenberg, M. (1965). Society and the adolescent self-image. Princeton, NJ: Princeton University Press.

Rotter, J. B. (1966). Generalized expectancies for internal versus external control of reinforcement. Psychological Monographs, 80 (1, Whole No. 609).

Rubin, Z., \& Peplau, L. A. (1975). Who believes in a just world? Journal of Social Issues, 31, 65-89.

Smith, P. C. (1955). The prediction of individual differences in susceptibility to industrial monotony. Journal of Applied Psychology, 39, 322-329.
Smith, P. C., Kendall, L., \& Hulin, C. L. (1969). The measurement of satisfaction in work and retirement. Chicago: Rand McNally.

Spector, P. E. (1982). Behavior in organizations as a function of employee's locus of control. Psychological Bulletin, 91, 482-497.

Staw, B. M., Bell, N. E., \& Clausen, J. A. (1986). The dispositional approach to job attitudes: A lifetime longitudinal test. Administrative Science Quarterly, 31, 56-77.

Staw, B. M., \& Ross, J. (1985). Stability in the midst of change: A dispositional approach to job attitudes. Journal of Applied Psychology, 70, 469-480.

Swann, W. B., Jr. (1992). Seeking "truth," finding despair: Some unhappy consequences of a negative self-concept. Current Directions in Psychological Science, 1, 15-18.

Swann, W. B., Jr., Stein-Seroussi, A., \& Giesler, R. B. ( 1992). Why people self-verify. Journal of Personality and Social Psychology, 62, 392-401.

Taylor, S. E., \& Brown, J. D. (1988). Illusions and well-being: A social psychological perspective on mental health. Psychological Bulletin, 103, 193-210.

Watson, D., Clark, L. A., \& Tellegen, A. (1988). Development and validation of brief measures of positive and negative affect: The PANAS scales. Journal of Personality and Social Psychology, 54, 1063-1070.

Weiss, H. M., \& Cropanzano, R. (1996). Affective events theory: A theoretical discussion of the structure, causes, and consequences of affective experiences at work. Research in Organizational Behavior, 18, 1-74.

Weitz, J. (1952). A neglected concept in the study of job satisfaction. Personnel Psychology, 5, 201-205.

Received August 8, 1996

Revision received August 10, 1997

Accepted August 18, 1997 